\title{
Anti-inflammatory effect of Morinda citrifolia leaf extract on macrophage RAW 264.7 cells
}

\author{
Aurasorn Saraphanchotiwitthaya ${ }^{\mathrm{a}, \mathrm{b}, *}$, Pattana Sripalakit ${ }^{\mathrm{b}, \mathrm{c}}$ \\ a Department of Pharmaceutical Technology, Faculty of Pharmaceutical Sciences, Naresuan University, \\ Phitsanulok 65000 Thailand \\ b Pharmaceutical Biotechnology Research Unit, Faculty of Pharmaceutical Sciences, Naresuan University, \\ Phitsanulok 65000 Thailand \\ c Department of Pharmaceutical Chemistry and Pharmacognosy, Faculty of Pharmaceutical Sciences, \\ Naresuan University, Phitsanulok 65000 Thailand
}

*Corresponding author, e-mail: aurasorns@nu.ac.th

ABSTRACT: Leaves of Morinda citrifolia (Rubiaceae) have been used in folk medicine to treat pain and inflammation. In this study, the anti-inflammatory activity of $M$. citrifolia leaf extracts was investigated. The extract was prepared by freeze-drying juice squeezed from $M$. citrifolia leaves. HPLC analysis of the crude extract revealed rutin to be a major compound together with small amounts of quercetin and kaempferol. The effect of this extract on TNF- $\alpha$, IL- $1 \beta$, and NO secretion by lipopolysaccharide-induced macrophage RAW 264.7 cells was investigated and compared to that of rutin, dexamethasone, and indomethacin. The results show that the extract inhibited TNF- $\alpha$ (98\%, $750 \mu \mathrm{g} / \mathrm{ml})$ secretion four times more than dexamethasone $(3.92 \mu \mathrm{g} / \mathrm{ml})$ and indomethacin $(3.58 \mu \mathrm{g} / \mathrm{ml})$, while rutin had no effect. The extract suppressed IL-1 $\beta$ secretion in a dose-dependent fashion with a maximum inhibition of about $79 \%(750 \mu \mathrm{g} / \mathrm{ml})$. This was similar to that achieved by dexamethasone $(97 \%, 3.92 \mu \mathrm{g} / \mathrm{ml})$, indomethacin $(70 \%, 3.58 \mu \mathrm{g} / \mathrm{ml})$, and rutin $(90 \%, 48.84 \mu \mathrm{g} / \mathrm{ml})$. Moreover, the extract inhibited NO secretion $(74 \%, 750 \mu \mathrm{g} / \mathrm{ml}) 50 \%$ more than rutin $(40 \mu \mathrm{M})$ and $70 \%$ more than dexamethasone and indomethacin $(10 \mu \mathrm{M})$. This study demonstrates the potential of $M$. citrifolia leaves as an effective therapeutic intervention against inflammatory diseases.

KEYWORDS: noni leaves, TNF- $\alpha$, IL-1 $\beta$, nitric oxide

\section{INTRODUCTION}

Inflammation is the first response of the immune system to infection or irritation, and plays important pathological roles in the development of diseases such as cancer, diabetes, atherosclerosis, and arthritis ${ }^{1}$. In inflammation, macrophages have three major functions: antigen presentation, phagocytosis, and immunomodulation through the production of various cytokines and growth factors. Macrophages play a critical role in the initiation, maintenance, and resolution of inflammation as they are activated and deactivated by the inflammatory process ${ }^{2}$. Macrophages produce various pro-inflammatory cytokines and inflammatory molecules that play a crucial role during the inflammatory process. However, overproduction of pro-inflammatory cytokines and inflammatory molecules by activated macrophages is critical to the onset of inflammation ${ }^{3}$. In the presence of stimuli such as lipopolysaccharides (LPS), activated macrophages produce various cytokines such as tumour necrosis factor- $\alpha$ (TNF- $\alpha$ ), interleu- kin-1 $\beta$ (IL-1 $\beta$ ), interleukin-6 (IL-6), and interleukin-10 (IL-10), and inflammatory mediators such as nitric oxide (NO) and prostaglandin E2 (PGE2) ${ }^{4-6}$. In our study, LPS was therefore used to activate macrophages to evaluate the anti-inflammatory effects of the leaf extract.

Non-steroidal anti-inflammatory drugs and steroidal drugs are widely used to treat several inflammatory conditions; however, their ability to cause many and severe adverse effects limits their uses. In this regard, traditional medicine continues to use medicinal plants as a substitute for allopathic medicine ${ }^{7,8}$.

Plant-derived extracts have historically been considered to be effective at maintaining vitality, preventing and treating various diseases, and enhancing overall immune health ${ }^{9}$. Morinda citrifolia Linn. (Rubiaceae family) or noni ('yo' in Thai) is a small tropical tree that grows widely in Polynesia. It has been used in folk remedies for over 2000 years. All parts of the plant, including the leaves, fruit, bark, and roots have several pharmacological prop- 
erties $^{10}$. Medical applications of this plant are based on its anti-inflammatory ${ }^{11}$, anti-cancer ${ }^{12}$, and antioxidant properties ${ }^{13}$. Its fruits have been used as a folk medicine for the treatment of many diseases including diabetes, high blood pressure, inflammation, and cancer ${ }^{14}$. In 2002, noni juice was accepted in the European Union as a novel food and the noni juice market continues to grow ${ }^{11}$. Noni fruits contain active components such as phenolic compounds, in particular, coumarin, flavonoid, and iridoid compounds ${ }^{15}$. The leaves are also the source of a variety of other health-promoting commercial products available in Japan and the US, mainly for used to make infusions. Some manufacturers also produce capsules containing powdered noni leaves ${ }^{16}$. Previous studies revealed that noni leaves contain a variety of phytochemical constituents, including terpenoid, phytosterol, iridoid, flavonol, and anthraquinone compounds and their glycoside derivatives ${ }^{17-19}$. Flavonoid compounds have been indicated to possess a variety of biological activities $^{20,21}$, and may play an important role in noni leaves.

The aim of this study was to investigate the therapeutic potential of an aqueous extract of $M$. citrifolia leaves against inflammation and to determine the possibility of using that extract as a commercial health-promoting product. We studied the effect of the extract on the production of TNF- $\alpha$, IL- $1 \beta$, and NO by LPS-induced macrophage RAW 264.7 cells, and compared them with the effects of rutin and two anti-inflammatory drugs (dexamethasone and indomethacin).

\section{MATERIALS AND METHODS}

\section{Plant material}

M. citrifolia was collected in January 2012 in Lamphun province, Thailand, and authenticated by a botanist from the Office of the Forest Herbarium, Department of National Parks, Wildlife and Plant Conservation, Bangkok, Thailand. A voucher specimen (183646) was also prepared and deposited at the Office of the Forest Herbarium, Department of National Parks, Wildlife and Plant Conservation, Bangkok, Thailand.

\section{Chemicals}

Lipopolysaccharide (LPS), Dulbecco's modified Eagle medium (DMEM), trypan blue dye, rutin, quercetin, and kaempferol were purchased from SigmaAldrich (St. Louis, MO, USA). Dimethyl sulphoxide (DMSO), phosphate buffer saline (PBS), dexam- ethasone, indomethacin, trypsin-EDTA, $N$-(1-naphthyl) ethylenediamine, and antibiotic-antimycotic solution (100 U penicillin, $100 \mu \mathrm{g}$ streptomycin, and $0.25 \mu \mathrm{g}$ amphotericin B per $\mathrm{ml}$ ) were purchased from Sigma-Aldrich (Dorset, UK). Foetal bovine serum was purchased from GIBCO/BRL Invitrogen (Paisley, Scotland). TNF- $\alpha$ and IL-1 $\beta$ ELISA kits were from eBioscience Inc. (San Diego, USA). Phosphoric acid, $85 \% \mathrm{v} / \mathrm{v}$, was from Carlo Erba (Milan, Italy). $\mathrm{NaNO}_{3}$ and sulphanilic acid were from Univar (NSW, Australia). Acetic acid, acetonitrile and methanol were purchased from Labscan (Samut Sakhon, Thailand).

\section{Preparation of aqueous extract of $M$. citrifolia leaves}

Fresh leaves of M. citrifolia were cleaned with tap water and rinsed with distilled water. The leaves (500 g) were chopped into small pieces and homogenized with distilled water (1 l l). Leaf juice was filtered and concentrated by freeze-drying. The extract was dissolved in $0.1 \%(\mathrm{v} / \mathrm{v})$ DMSO in PBS solution. Insoluble material was centrifuged and the extract was sterilized by passing through a $0.2 \mu \mathrm{m}$ filter. DMSO 0.1\% (v/v) in PBS solution was used as a control in all experiments.

\section{Cell culture}

Macrophage RAW 264.7 cells were obtained from the American Type Culture Collection. Cells were cultured in phenol red-free Dulbecco's modified Eagle medium (DMEM) supplemented with 100 unit$\mathrm{s} / \mathrm{ml}$ penicillin, $100 \mu \mathrm{g} / \mathrm{ml}$ streptomycin, and $10 \%$ heat-inactivated foetal bovine serum at $37^{\circ} \mathrm{C}$ with $5 \% \mathrm{CO}_{2}$. Cells were washed with DMEM medium and detached with $0.25 \%$ trypsin-EDTA. The cells were resuspended in DMEM medium at a density of $2 \times 10^{6}$ cells $/ \mathrm{ml}$. Viability was determined via the trypan blue dye technique. For IFN- $\gamma$, IL- $1 \beta$, and NO production assay, cells were seeded at $2 \times 10^{5}$ cells $/ 100 \mu \mathrm{l}$ in 96-well plates and incubated for $1 \mathrm{~h}$. After that, the cells were activated with $5 \mu \mathrm{g} / \mathrm{ml}$ LPS with or without test compounds (plant extract, rutin, and anti-inflammatory drugs; dexamethasone and indomethacin) for $48 \mathrm{~h}$. The supernatant was removed and assayed using a commercial enzymelinked immunosorbent assay (ELISA) kit.

\section{HPLC analysis}

The HPLC system consisted of an LC-20AT pump (Shimadzu, Kyoto, Japan), an SPD-20A UV detector (Shimadzu, Kyoto, Japan), equipped with an SPD-20A system controller (Shimadzu, Kyoto, 
Japan), and an SIL-10ADVP sample injector (Shimadzu, Kyoto, Japan) fitted with a $20 \mu \mathrm{l}$ sample loop. The chromatographic separations were carried out on a Luna C18 column $(250 \mathrm{~mm} \times 4.6 \mathrm{~mm}$ i.d., $5 \mu \mathrm{m}, 250 \AA$ from Phenomenex, USA). The mobile phase was methanol-acetonitrile-water (40:15:45, v/v/v) containing 1\% (v/v) acetic acid. All separations were performed isocratically at a flow rate of $1 \mathrm{ml} / \mathrm{min}$. Column temperature was maintained at room temperature $\left(27 \pm 2{ }^{\circ} \mathrm{C}\right)$. The peaks were determined using a UV detector set at a wavelength of $365 \mathrm{~nm}$ based on a previous report $^{22}$. Compounds were identified by comparing their retention times and UV-Vis spectral data of the peaks detected with those of original reference standards. Quantification was accomplished using external calibration with pure standards. The calibration curves were linear with $r^{2}=0.999$.

Standard solutions of three flavonoid compounds (rutin, quercetin, and kaempferol) were prepared in methanol, at concentrations of 10$330 \mu \mathrm{g} / \mathrm{ml}$. The dried extract was dissolved in the mobile phase. After filtering through a filter paper and a $0.45-\mu \mathrm{m}$ membrane filter, the extract was injected directly.

\section{LPS-induced cytokine production assay}

Production of mouse TNF- $\alpha$ and IL- $1 \beta$ was measured via ELISA according to the manufacturer's instructions. Briefly, a 96-well microtitre plate was pre-coated overnight with capture antibody. After blocking and several washings, $100 \mu \mathrm{l}$ of working standards and samples were then added for incubation for $2 \mathrm{~h}$. After washing, $100 \mu \mathrm{l}$ of working detector solution containing biotinylated anti-mouse cytokine monoclonal antibody was added and incubated for $1 \mathrm{~h}$. After further washing, $100 \mu \mathrm{l}$ of avidin-horseradish peroxidase conjugate was added to each well and incubated for $30 \mathrm{~min}$. Then, $100 \mu \mathrm{l}$ of substrate solution was added and the culture was incubated for $15 \mathrm{~min}$, followed by the addition of $50 \mu \mathrm{l}$ of stop solution, and the absorbance was read within $30 \mathrm{~min}$ using a microplate reader at $450 \mathrm{~nm}$. The inhibition of cytokine production compared to the control (LPS) was calculated as: $\left([\text { cytokine }]_{\mathrm{c}}-[\text { cytokine }]_{\mathrm{t}}\right) /[\text { cytokine }]_{\mathrm{c}}$, where $[\text { cytokine }]_{\mathrm{c}}$ and [cytokine $]_{\mathrm{t}}$ are the cytokine concentration in the control and test sample, respectively.

\section{Nitrite assay}

The presence of nitrite, a stable oxidized product of nitric oxide (NO), was determined in cell culture media using Griess reagent ${ }^{23}$. Briefly, $50 \mu \mathrm{l}$ of supernatant from the test culture was mixed with $50 \mu \mathrm{l}$ of $1 \%(\mathrm{w} / \mathrm{v})$ sulphanilic acid in $5 \%(\mathrm{v} / \mathrm{v})$ phosphoric acid in a 96-well plate, followed by incubation for $10 \mathrm{~min}$ at room temperature. After that $50 \mu 1 \quad 0.1 \%(\mathrm{w} / \mathrm{v}) \quad \mathrm{N}$-1-naphthylethylenediamine $\mathrm{HCl}$ in distilled water was added and incubated for $10 \mathrm{~min}$ at room temperature. The optical density at $540 \mathrm{~nm}$ was measured with a microplate reader. The NO concentration was calculated by comparison with a $\mathrm{NaNO}_{2}(0-100 \mu \mathrm{M})$ standard curve. The final concentration of DMSO was adjusted to less than $0.1 \%$ for all treatments. Dexamethasone and indomethacin were used as a reference standard. The results were expressed as inhibition of NO production compared to the control (LPS) using: ([nitrite $\left.]_{\mathrm{c}}-[\text { nitrite }]_{\mathrm{t}}\right) /[\text { nitrite }]_{\mathrm{c}}$, where $[\text { nitrite }]_{\mathrm{c}}$ and $[\text { nitrite }]_{\mathrm{t}}$ are the nitrite concentration in the control and test sample, respectively.

\section{Statistical analysis}

One-way ANOVA followed by Tukey's post-hoc test were used to determine the statistical significance of differences between the values for the various experimental and control groups. Data were expressed as mean \pm S.D. and the results were taken from three independent experiments performed in triplicate. Values of $p<0.05$ were considered statistically significant.

\section{RESULTS}

\section{Plant extraction}

The extract (FMC_CF) was obtained by freeze-drying the aqueous juice obtained from fresh $M$. citrifolia leaves. The physical appearance of the extract was a viscous greenish-brown gum and the yield was $8 \%(\mathrm{w} / \mathrm{w})$ of fresh leaves.

\section{Quantitative analysis of flavonoid compounds by HPLC}

Rutin, quercetin, and kaempferol in M. citrifolia extract were analysed using HPLC. Methanol-acetonitrile-water $(40: 15: 45 \mathrm{v} / \mathrm{v} / \mathrm{v})$ containing $1 \%(\mathrm{v} / \mathrm{v})$ acetic acid system as the mobile phase demonstrated good separation of rutin, quercetin, and kaempferol at the retention time of $4.1,9$, and $14 \mathrm{~min}$, respectively. Comparison of the retention times of the peaks detected from HPLC chromatograms of $100 \mathrm{mg} / \mathrm{ml} \mathrm{M}$. citrifolia extract to those of reference standard phytochemicals revealed that rutin was the major compound $(0.37 \%(\mathrm{w} / \mathrm{w})$ of extract) with a small amount of quercetin and kaempferol (less 

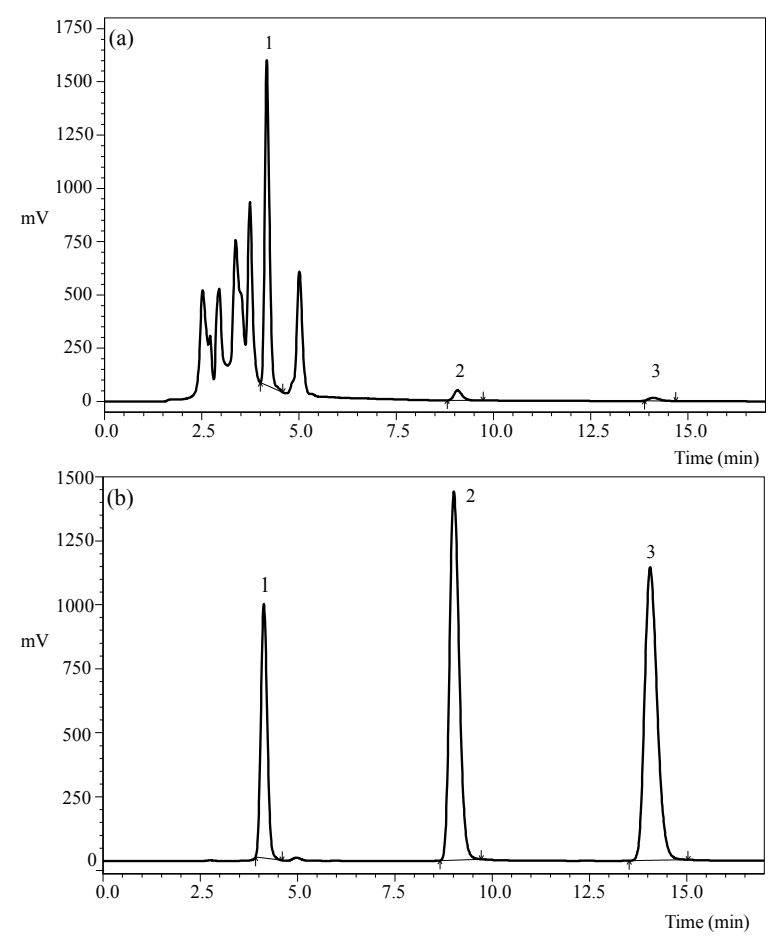

Fig. 1 HPLC chromatogram of (a) M. citrifolia leaf extract (FMC_CF) at $100 \mathrm{mg} / \mathrm{ml}$ and (b) standard rutin (peak 1), quercetin (peak 2), and kaempferol (peak 3) at $0.33 \mathrm{mg} / \mathrm{ml}$ showing a retention time of $4.1,9$, and $14 \mathrm{~min}$, respectively.

than $0.01 \%(w / w)$ of extract). The HPLC chromatogram of the extract is shown in Fig. 1.

\section{M. citrifolia extract inhibited IL-1 $\beta$, TNF- $\alpha$, and NO production from macrophage RAW 264.7 cells}

The secretion of TNF- $\alpha$ and IL- $1 \beta$ from mouse macrophage RAW 264.7 cell cultures treated with M. citrifolia extract, in comparison with rutin, was assayed using ELISA. The commercial inflammatory agents, dexamethasone, and indomethacin, were used as a positive control. Stimulation of RAW 264.7 cells with LPS $(5 \mu \mathrm{g} / \mathrm{ml})$ significantly increased secreted TNF- $\alpha$ and IL-1 $\beta$ levels of approximately 3 -folds over basal secretion values and these increases were substantially inhibited by rutin, dexamethasone, and indomethacin, and by $M$. citrifolia extract.

The extract significantly inhibited the secretion of TNF- $\alpha$ from LPS-induced macrophages. The maximum suppression of approximately $98 \%$ presented by the extract at $750 \mu \mathrm{g} / \mathrm{ml}$ was observed, and was much higher than that of dexamethasone $(23 \%$ at
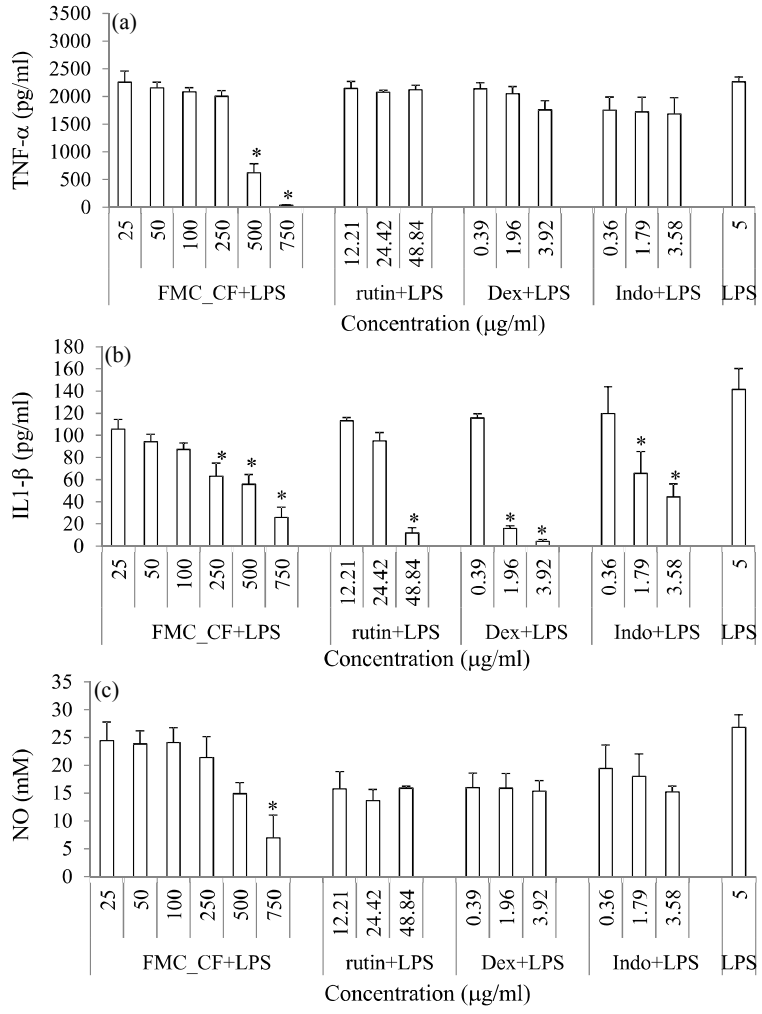

Fig. 2 Effect of $M$. citrifolia extract (FMC_CF), rutin, dexamethasone (dex), and indomethacin (indo) on (a) TNF- $\alpha$, (b) IL-1 $\beta$, and (c) nitric oxide (NO) production by macrophage RAW 264.7 cells stimulated with $5 \mu \mathrm{g} / \mathrm{ml}$ lipopolysaccharide (LPS). Each value represents the mean \pm S.D. of triplicates compared to LPS; * $p<0.05$.

$3.92 \mu \mathrm{g} / \mathrm{ml}, p<0.05)$ and indomethacin $(25 \%$ at $3.58 \mu \mathrm{g} / \mathrm{ml}, p<0.05)$. At the tested concentrations, rutin did not have any effect on TNF- $\alpha$ production. The results are shown in Fig. 2a.

The extract showed maximal inhibition of IL-1 $\beta$ production $(79 \%)$ at $750 \mu \mathrm{g} / \mathrm{ml}$; this was not statistically different from the maximal inhibition produced by dexamethasone $(97 \%$ at $3.92 \mu \mathrm{g} / \mathrm{ml})$, indomethacin $(70 \%$ at $3.58 \mu \mathrm{g} / \mathrm{ml})$, and rutin $(90 \%$ at $48.84 \mu \mathrm{g} / \mathrm{ml})$. Comparison of the $\mathrm{IC}_{50}$ values revealed that the potency of inhibition of IL-1 $\beta$ production of the extract $(294 \mu \mathrm{g} / \mathrm{ml})$ was much weaker than that of rutin $(30.2 \mu \mathrm{g} / \mathrm{ml})$, dexamethasone $(0.93 \mu \mathrm{g} / \mathrm{ml})$, and indomethacin $(1.50 \mu \mathrm{g} / \mathrm{ml})$, respectively. These results are shown in Fig. $2 b$.

NO production increased upon LPS-stimulation, and this increase was suppressed by rutin, dexamethasone, indomethacin and the M. citrifolia extract. The inhibitory effect of the latter on NO 
production increased with dose, with the maximal inhibition of about $74 \%(750 \mu \mathrm{g} / \mathrm{ml})$ and an $\mathrm{IC}_{50}$ value of $527 \mu \mathrm{g} / \mathrm{ml}$. Rutin, dexamethasone, and indomethacin moderately reduced nitrite accumulation with the highest reduction being approximately $40-50 \%$. The results are shown in Fig. 2c.

\section{DISCUSSION}

The inflammatory response is a dynamic process involving complex interactions among inflammatory molecules that arise in any tissue in response to traumatic, infectious, post-ischaemic, toxic, or auto-immune injury ${ }^{24}$. We have previously studied the immunomodulatory activity of $M$. citrifolia extracts prepared using various techniques on human MOLT-4 cells. We found that the extract prepared by freeze-drying of aqueous juice led to a low IFN- $\gamma /$ IL-10 ratio, indicating anti-inflammatory activity (unpublished data). The present study was conducted to confirm the anti-inflammatory activity of $M$. citrifolia extract in vitro, by analysing its inhibitory effects on TNF- $\alpha$, IL- $1 \beta$, and NO production by RAW 264.7 macrophage cells. We compared its effect with that of rutin, a major component of $M$. citrifolia leaves ${ }^{25}$, and two anti-inflammatory agents (dexamethasone and indomethacin) as reference drugs. LPS was used to stimulate RAW 264.7 macrophages to produce pro-inflammatory mediators (TNF- $\alpha$, IL-1 $\beta$, and NO).

TNF- $\alpha$ and IL- $1 \beta$ are pro-inflammatory cytokines that are known to contribute to tissue damage and multiple organ failure. They are significant initiators of the inflammatory response and mediators of the development of various inflammatory diseases $^{26,27}$. TNF- $\alpha$ is secreted by macrophages and can be induced by LPS. TNF- $\alpha$ plays a key role in the induction and perpetuation of inflammation and upregulation of other pro-inflammatory cytokines and endothelial adhesion molecules ${ }^{28}$. The production of TNF- $\alpha$ increases the release of IL- $1 \beta^{29,30}$ and is crucially required for the synergistic induction of $\mathrm{NO}$ synthesis in LPS-stimulated macrophages ${ }^{31}$.

In our study, macrophages treated with various concentrations of $M$. citrifolia leaf extract showed a concentration-dependent decrease in TNF- $\alpha$ and IL-1 $\beta$ production in LPS-stimulated RAW 264.7 cells. The extract significantly inhibited TNF- $\alpha$ production (four-fold more inhibition than that produced by dexamethasone and indomethacin), while rutin had no effect. The extract inhibited IL- $1 \beta$ production with moderate to high potency. Its potency was slightly lower than that of rutin and dexamethasone but slightly higher than that of indomethacin.
NO is a signalling molecule that plays a key role in the pathogenesis of inflammation, and is considered a pro-inflammatory mediator due to its overexpression in abnormal situations. The transcription of iNOS, and thus NO production, is increased in activated macrophages ${ }^{32}$. At adequate concentrations, NO can generate or modify intracellular signals, thereby affecting the function of immune cells, as well as tumour cells and resident cells of different tissues and organs. However, its uncontrolled release can cause the inflammatory destruction of target tissue during an infection ${ }^{33}$. In this study, NO production was assessed by measuring the accumulation of nitrites, a stable metabolite of NO, in the media via a colorimetric assay based on the Griess reaction. Our study showed that the extract markedly downregulated LPS-induced NO production along with that of pro-inflammatory cytokines (TNF- $\alpha$ and IL-1 $\beta$ ) in macrophages. The extract considerably reduced NO production by LPSinduced macrophages, 1.53 -fold more than rutin and 1.7-fold more than dexamethasone and indomethacin.

According to the trypan blue exclusion test, the viability of macrophages treated with the extract and test compounds was more than $90 \%$. This indicated that the reduction in TNF- $\alpha$, IL- $1 \beta$ and nitrite concentration was not due to a cytotoxic effect.

The HPLC analysis revealed that the $M$. citrifolia leaf extract contained the flavonoid compounds rutin, quercetin, and kaempferol, in accordance with a previous report ${ }^{25}$. From this study, rutin $(0.37 \%(\mathrm{w} / \mathrm{w})$ of the extract) was the major compound in $M$. citrifolia leaves together with a small amount of quercetin and kaempferol (less than $0.01 \%(\mathrm{w} / \mathrm{w})$ of the extract). Phenolic compounds are plant secondary metabolites known for their anti-oxidative and anti-inflammatory properties. Accordingly, flavonoid compounds such as kaempferol and quercetin aglycones, and glycosides have anti-inflammatory effects in vitro ${ }^{34,35}$, involving inhibition of NO and PGE2 production by activated macrophages. Quercetin has been demonstrated to possess anti-inflammatory activities ${ }^{20,36}$ and could be, at least in part, responsible for the anti-inflammatory effect. Moreover, rutin was no more active against inflammation than the extract, determining by comparison of the equivalent concentrations ( 25 and $50 \mu \mathrm{g} / \mathrm{ml}$ ). One possible explanation could be that the extract contains more chemical constituents that could act in a synergistic or antagonistic manner. Thus the active doses of 
the plant extract were higher than those of the pure compounds or reference drugs. It is well known that flavonoid compounds have a biological effect; the combination of flavonoids in the crude extract may act synergistically, thus amplifying the final effect.

In conclusion, the $M$. citrifolia extract demonstrated anti-inflammatory effects in vitro. The presence of flavonoid compounds would partially explain this activity and the combination of several compounds might boost the pharmacological potential of $M$. citrifolia leaf extract. $M$. citrifolia leaves have therefore a therapeutic potential that supports its use in traditional Thai medicine, and could thus be developed as a commercial anti-inflammatory. The signalling mechanism by which the extract exerts its anti-inflammatory effects on immune cell functions in vitro now needs to be investigated.

Acknowledgements: This work was financially supported by Research Funds from Yearly Budget, Naresuan University (Grant no. R2556B040), Thailand.

\section{REFERENCES}

1. Aggarwal B, Shishodia S, Takada Y, Jackson-Bernitsas D, Ahn S, Sethi G, Ichikawa H (2006) TNF blockade: an inflammatory issue. In: Numerof R, Dinarello DA, Asadullah K (eds) Cytokines as Potential Therapeutic Targets for Inflammatory Skin Diseases, Ernst Schering Research Foundation Workshop, Springer, Berlin, pp 161-86.

2. Fujiwara N, Kobayashi K (2005) Macrophages in inflammation. Curr Drug Targets Inflamm Allergy 4, 281-6.

3. Allam R, Anders HJ (2008) The role of innate immunity in autoimmune tissue injury. Curr Opin Rheumatol 20, 538-44.

4. Mongan LC, Jones T, Patrick G (2000) Cytokine and free radical responses of alveolar macrophages in vitro to asbestos fibres. Cytokine 12, 1243-7.

5. Posadas I, Terencio MC, Guillén I, Ferrándiz ML, Coloma J, Payá M, Alcaraz MJ (2000) Co-regulation between cyclo-oxygenase- 2 and inducible nitric oxide synthase expression in the time-course of murine inflammation. $N$ Schmied Arch Pharmacol 361, 98-106.

6. Guha M, Mackman N (2001) LPS induction of gene expression in human monocytes. Cell Signal 13, 85-94.

7. Pinheiro M, Fernandes S, Fingolo C, Boylan F, Fernandes P (2013) Anti-inflammatory activity of ethanol extract and fractions from Couroupita guianensis Aublet leaves. $J$ Ethnopharmacol 146, 324-30.

8. Poetker DM, Reh DD (2010) A comprehensive review of the adverse effects of systemic corticosteroids. Otolaryngol Clin N Am 43, 753-68.
9. Spencer JW (1999) Essential issues in complementary/alternative medicine. In: Jacobs JJ (ed) Complementary/Alternative Medicine: an Evidence-Based Approach, Mosby, St. Louis, pp 3-36.

10. Li R, Myers S, Leach D, Lin G, Leach G (2003) A cross-cultural study: anti-inflammatory activity of Australian and Chinese plants. J Ethnopharmacol 85, 23-32.

11. Dussossoy E, Brat P, Bony E, Boudard F, Poucheret P, Mertz C, Giaimis J, Michel A (2011) Characterization, anti-oxidative and anti-inflammatory effects of Costa Rican noni juice (Morinda citrifolia L.). $J$ Ethnopharmacol 133, 108-15.

12. Hirazumi A, Furusawa E, Chou SC, Hokama Y (1994) Anticancer activity of Morinda citrifolia (noni) on intraperitoneally implanted Lewis lung carcinoma in syngenic mice. Proc West Pharmacol Soc 37, 145-6.

13. Zin ZM, Hamid AA, Osman A, Saari N (2006) Antioxidative activities of chromatographic fractions obtained from root, fruit and leaf of Mengkudu (Morinda citrifolia L.). Food Chem 94, 169-78.

14. Chan-Blanco Y, Vaillant F, Perez AM, Reynes M, Brillouet JM, Brat P (2006) The noni fruit (Morinda citrifolia L.): a review of agricultural research, nutritional and therapeutic properties. J Food Compos Anal 19, 645-54.

15. Potterat O, von Felten R, Dalsgaard PW, Hamburger $M$ (2007) Identification of TLC markers and quantification by HPLC-MS of various constituents in noni fruit powder and commercial noni-derived products. J Agr Food Chem 55, 7489-94.

16. West BJ, Tani H, Palu AK, Tolson CB, Jensen CJ (2007) Safety tests and antinutient analyses of noni (Morinda citrifolia L.) leaf. J Sci Food Agr 87, 2583-8.

17. Sang S, Cheng X, Zhu N, Stark RE, Badmaev VG, Ghai $G$, et al (2001) Flavonol glycosides and novel iridoid glycoside from the leaves of Morinda citrifolia. J Agri Food Chem 49, 4478-81.

18. Sang S, Liu G, He K, Zhu N, Dong Z, Zheng Q, Rosen R, Ho C (2003) New unusual iridoids from the leaves of Noni (Morinda citrifolia L.) show inhibitory effect on ultraviolet B-induced transcriptional activator protein-1 (AP-1) activity. Bioorg Med Chem 11, 2499-502.

19. Takashima J, Ikeda Y, Komiyama K, Hayashi M, Kishida A, Ohsaki A (2007) New constituents from the leaves of Morinda citrifolia. Chem Pharmaceut Bull 55, 343-5.

20. García-Mediavilla V, Crespo I, Collado PS, Esteller A, Sánchez-Campos S, Tuñón MJ, González-Gallego $\mathrm{J}$ (2007) The anti-inflammatory flavones quercetin and kaempferol cause inhibition of inducible nitric oxide synthase, cyclooxygenase- 2 and reactive C-protein, and down-regulation of the nuclear factor kappa B pathway in Chang Liver cells. Eur J Pharmacol 557, 221-9.

21. Kampkötter A, Nkwonkam CG, Zurawski RF, Timpel 
C, Chovolou Y, Wätjen W, Kahl R (2007) Investigations of protective effects of the flavonoids quercetin and rutin on stress resistance in the model organism Caenorhabditis elegans. Toxicology 234, 113-23.

22. Zu Y, Li C, Fu Y, Zhao C (2006) Simultaneous determination of catechin, rutin, quercetin, kaempferol and isorhamnetin in the extract of sea buckthorn (Hippophae rhamnoides L.) leaves by RP-HPLC with DAD. J Pharmaceut Biomed Anal 41, 714-9.

23. Diouf P, Stevanovic T, Cloutier A (2009) Study on chemical composition, antioxidant and anti-inflammatory activities of hot water extract from Picea mariana bark and its proanthocyanidin-rich fractions. Food Chem 113, 897-902.

24. Zedler S, Faist E (2006) The impact of endogenous triggers on trauma-associated inflammation. Curr Opin Crit Care 12, 595-601.

25. Deng S, West BJ, Jensen J (2008) Simultaneous characterization and quantitation of flavonol glycosides and glycones in noni leaves using a validated HPLCUV/MS method. Food Chem 111, 526-9.

26. Glauser MP (1996) The inflammatory cytokines. New developments in the pathophysiology and treatment of septic shock. Drugs 52, 9-17.

27. Männel DN, Echtenacher B (2000) TNF in the inflammatory response. In: Jack RS (ed) CD14 in the Inflammatory Response. Chemical Immunology and Allergy Vol. 74, Karger, Basel, pp 141-61.

28. Beutler B, Cerami A (1989) The biology of cachectin/TNF-a primary mediator of the host response. Annu Rev Immunol 7, 625-55.

29. Molloy RG, Mannick JA, Rodrick ML (1993) Cytokines, sepsis and immunomodulation. Br J Surg 80, 289-97.

30. West MA, Seatter SC, Bellingham J, Clarir L (1995) Mechanisms of reprogrammed macrophage endotoxin signal transduction after lipopolysaccharide pretreatment. Surgery 118, 220-8.

31. Aggarwal BB, Natarajan K (1996) Tumor necrosis factors: developments during the last decade. Eur Cytokine Netw 7, 93-124.

32. Alley EB, Murphy WJ, Russell SW (2005) A classical enhancer element responsive to both lipopolysaccharide and interferon- $\gamma$ augments induction of the iNOS gene in mouse macrophages. Gene 158, 247-51.

33. Kim ND, Kim EM, Kang KW, Cho MK, Choi SY, Kim SG (2003) Ginsenoside Rg3 inhibits phenylephrineinduced vascular contraction through induction of nitric oxide synthase. Br J Pharmacol 140, 661-70.

34. Blonska M, Bronikowska J, Pietsz G, Czuba ZP, Scheller S, Krol W (2004) Effects of ethanol extract of propolis (EEP) and its flavones on inducible gene expression in J774A.1 macrophages. J Ethnopharmacol 91, 25-30.

35. Wang GJ, Chen YM, Wang TM, Lee CK, Chen KJ, Lee TH (2008) Flavonoids with iNOS inhibitory activity from Pogonatherum crinitum. J Ethnopharmacol 118,
71-8.

36. Lin HY, Juan SH, Shen SC, Hsu FL, Chen YC (2003) Inhibition of lipopolysaccharide-induced nitric oxide production by flavonoids in RAW264.7 macrophages involves heme oxygenase-1. Biochem Pharmacol 66, 1821-32. 